\title{
Groklaw - Where We Have Been and Where We Are Going
}

\author{
Mark Webbink, \\ Groklaw editor since May 2011
}

DOI: 10.5033 /ifosslr.v3i1.60

\begin{abstract}
After 8 years documenting litigation, explaining complicated legal matters and debunking uncertainty in the field of FOSS, Pamela Jones passed the baton on the Groklaw.net news website over to Mark Webbink. Under his editorship, Groklaw 2.0 will remain committed to its values and accuracy in reporting, though it will increasingly engage with issues like patent litigation to reflect current market tensions and imperatives.
\end{abstract}

\section{Keywords}

Law; information technology; Free and Open Source Software; Free Software community; patent litigation

On May 16, 2011, Groklaw ${ }^{1}$ celebrated its eighth anniversary, and on that same day something unique happened - Pamela Jones stepped down as the editor of Groklaw, a role she had held since she started the electronic publication in 2003. But Groklaw did not shutter its doors on May 16. Rather, it entered a new era, what we are calling Groklaw 2.0, under the editorship of Mark Webbink, a name familiar to many in open source legal circles.

When Groklaw started in 2003, it was focused almost exclusively on one thing: exposing the story behind the SCO Group and its path of litigation. Day after day Pam and her team of open source journalists ferreted out the facts and told the story of SCO, a story that still has not concluded. As Groklaw progressed, readers would ask about other aspects of free and open source software. Pam was always willing to oblige, tapping into a vast network of friends and experts to explain the difficult legal concepts that sometimes underly open source.

Along the way certain standards were established. First, Groklaw is a journalistic enterprise, with interviews, research, and reporting of legal events important to the FOSS community. Groklaw is not

1 Groklaw, http://www.groklaw.net 
without a point of view, but accuracy of reporting has always been the goal. Second, while Pam and Mark do most of the writing, they receive significant contributions from the many Groklaw volunteers, including research, reporting, document conversion, expertise, or whatever we need. These volunteers are legal experts, technology experts, educators, and journalists. They come from just about every walk of life.

As stated, Groklaw has a point of view that drives the stories and commentaries in which it has interest. Groklaw is a proponent of free and open source software, a proponent of truly open standards, an advocate against patents related to software, an advocate for low-cost, wide-spread access to the Internet, and an advocate for reasonable protection of privacy. That isn't to say that Groklaw is against other forms of software development or licensing, just that we believe the approaches we support are superior. Finally, Groklaw is for fair competition in the marketplace, which means we do not look kindly on FUD (fear, uncertainty and doubt) as a tool to promote one position over another.

Groklaw is also a wonderful historical archive of information and documents. Technologically supported by and operating on the servers of ibiblio ${ }^{2}$, all of the information that Groklaw gathers and publishes remains accessible to the public. Groklaw has years worth of litigation history, transcripts, court documents, legal references, and papers that may be of interest to either legal scholars or the average Joe simply trying to understand more about free and open source software and the battles that have been fought on its behalf. And, while Groklaw provides a great deal of legal information, it does not dispense legal advice. There are plenty of experienced open source attorneys for that.

So what is Groklaw 2.0 and what is changing? Initially, not that much. Groklaw is a tremendous enterprise that has accumulated eight years of stories, technology, and practices, and you just don't hand all of that off overnight. For the time being, we are in a period of transition and learning.

However, anyone who has been around Groklaw for awhile is likely already seeing subtle changes. Mark's style of writing is not the same as Pam's. That is neither good nor bad, it's just different. Second, Groklaw is focusing more and more on patent litigation that either directly or indirectly impacts the FOSS community. Part of that is because of Mark's background and interests, but a larger part of it is because that is where the information technology industry is today, deeply embedded in a morass of patent litigation.

As Groklaw eyes the future, there are some things clearly on the horizon. One is to expand its stable of writers. While Pam continues to write the occasional article and Mark is now doing the bulk of the writing, we want to engage other writers in this enterprise. So we are reaching out to both law students and legal practitioners to participate and contribute.

A bit longer term, we are looking at a possible change in our technology platform. While Geeklog, the blogging software on which Groklaw runs, has served us well, it is not as flexible as many of the tools now available for web publishing. We will remain committed to open source tools, but Drupal may be a better long-term platform for us.

Groklaw will also start to stretch its wings, moving from primarily covering U.S.-centric litigation to a

2 Ibiblio, http://www.ibiblio.org 
more international approach. But that means we need legal experts from around the world to support the work. We are hoping to work closely with the Freedom Task Force - Legal of the Free Software Foundation Europe. Just as the International Free and Open Source Software Law Review seeks to bring periodical, scholarly work to the public on FOSS and the IFOSS Law Book seeks to provide a reference volume on technology law and its application to FOSS, Groklaw looks to bring daily international news about FOSS. But that can only happen with a broad international effort.

One thing that won't change is the fact that Groklaw will continue to be what it always has been, a collaborative effort of volunteers. Come visit us, and sign up.

\begin{abstract}
About the authors
Mark Webbink is a lawyer with a strong focus on patent law and Free and Open Source Software. He is the former General Counsel at RedHat and one of the directors of the Software Freedom Law Center. As visiting professor at New York Law, Mark runs the Center for Patent Innovations, and oversees the Peer To Patent project run with the U.S. Patent and Trademark Office. He has been active in seeking reform of the U.S. patent system, and teaches patent licensing. In addition, Mark is a senior lecturing fellow at Duke University School of Law where he teaches about licensing.
\end{abstract}

See Jones, Pamela, 'As of Today, It's Mark Webbink's Groklaw 2.0', Groklaw, Monday, May 16 2011, http://www.groklaw.net/article.php?story=20110515173831922 


\section{Licence and Attribution}

This paper was published in the International Free and Open Source Software Law Review, Volume 3, Issue 1 (September 2011). It originally appeared online at http://www.ifosslr.org.

This article should be cited as follows:

Webbink, Mark (2011) 'Groklaw - Where We Have Been and Where We Are Going', International Free and Open Source Software Law Review, 3(1), pp 91 - 94

DOI: $\underline{10.5033 / \text { ifosslr.v3i1.60 }}$

Copyright (c) 2011 Mark Webbink.

This article is licensed under a Creative Commons UK (England and Wales) 2.0 licence, no derivative works, attribution, CC-BY-ND.

As a special exception, the author expressly permits faithful translations of the entire document into any language, provided that the resulting translation (which may include an attribution to the translator) is shared alike. This paragraph is part of the paper, and must be included when copying or translating the paper.

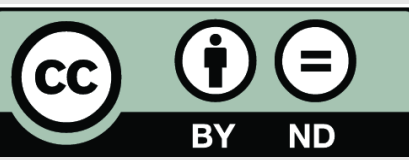

